\title{
Characterization of an Oct l orthologue in the channel catfish, Ictalurus punctatus: A negative regulator of immunoglobulin gene transcription?
}

\author{
Mara L Lennard ${ }^{\dagger 1}$, Jun-ichi Hikima ${ }^{\dagger 1}$, David A Ross ${ }^{\dagger 1}$, Corine P Kruiswijk ${ }^{\dagger 2}$, \\ Melanie R Wilson ${ }^{\dagger 3}$, Norman W Miller ${ }^{\dagger 3}$ and Gregory W Warr* ${ }^{* 1}$
}

Address: ${ }^{1}$ Marine Biomedicine and Environmental Sciences Center and Department of Biochemistry and Molecular Biology, Medical University of South Carolina, Charleston, SC 29425, USA, ${ }^{2}$ Cell Biology and Immunology Group, Wageningen Institute of Animal Sciences, Wageningen University, 6709 PG Wageningen, The Netherlands and ${ }^{3}$ Department of Microbiology, University of Mississippi Medical Center, Jackson, MS 39216, USA

Email: Mara L Lennard - lennard@musc.edu; Jun-ichi Hikima - junichi@musc.edu; David A Ross - david_ross3@merck.com; Corine P Kruiswijk - corine.kruiswijk@mac.com; Melanie R Wilson - mwilson@microbio.umsmed.edu; Norman W Miller - nmiller@microbio.umsmed.edu; Gregory W Warr* - warrgw@musc.edu

* Corresponding author †Equal contributors

Published: 31 January 2007

BMC Molecular Biology 2007, 8:8 doi:10.1 I86/147/-2199-8-8
Received: 20 October 2006

Accepted: 31 January 2007

This article is available from: http://www.biomedcentral.com/I47I-2199/8/8

(c) 2007 Lennard et al; licensee BioMed Central Ltd.

This is an Open Access article distributed under the terms of the Creative Commons Attribution License (http://creativecommons.org/licenses/by/2.0), which permits unrestricted use, distribution, and reproduction in any medium, provided the original work is properly cited.

\begin{abstract}
Background: The enhancer (E $\left.\mu 3^{\prime}\right)$ of the immunoglobulin heavy chain locus (IGH) of the channel catfish (Ictalurus punctatus) has been well characterized. The functional core region consists of two variant Oct transcription factor binding octamer motifs and one E-protein binding $\mu \mathrm{E} 5$ site. An orthologue to the Oct2 transcription factor has previously been cloned in catfish and is a functionally active transcription factor. This study was undertaken to clone and characterize the Octl transcription factor, which has also been shown to be important in driving immunoglobulin gene transcription in mammals.
\end{abstract}

Results: An orthologue of Oct I, a POU family transcription factor, was cloned from a catfish macrophage cDNA library. The inferred amino acid sequence of the catfish Octl, when aligned with other vertebrate Octl sequences, revealed clear conservation of structure, with the POU specific subdomain of catfish Octl showing $96 \%$ identity to that of mouse Oct I. Expression of Oct I was observed in clonal T and B cell lines and in all tissues examined. Catfish Octl, when transfected into both mammalian (mouse) and catfish B cell lines, unexpectedly failed to drive transcription from three different octamer-containing reporter constructs. These contained a trimer of octamer motifs, a fish $V_{H}$ promoter, and the core region of the catfish $E \mu 3^{\prime} I G H$ enhancer, respectively. This failure of catfish Octl to drive transcription was not rescued by human BOB.I, a co-activator of Oct transcription factors that stimulates transcription driven by catfish Oct2. When co-transfected with catfish Oct2, Octl reduced Oct2 driven transcriptional activation. Electrophoretic mobility shift assays showed that catfish Octl (native or expressed in vitro) bound both consensus and variant octamer motifs. Putative $\mathrm{N}$ - and $\mathrm{C}$-terminal activation domains of Octl, when fused to a Gal4 DNA binding domain and co-transfected with Gal4-dependent reporter constructs were transcriptionally inactive, which may be due in part to a lack of residues associated with activation domain function.

Conclusion: An orthologue to mammalian Octl has been found in the catfish. It is similar to mammalian Oct I in structure and expression. However, these results indicate that the physiological functions of catfish Octl differ from those of mammalian Octl and include negative regulation of transcription. 


\section{Background}

The octamer motif (ATGCAAAT) and its reverse complement [1] are important cis-regulatory elements found in transcriptional control regions of ubiquitously expressed genes, such as histone H2B and small nuclear RNAs (U1, U2, and U6), as well as cell-type specific genes, such as the immunoglobulin (IG) heavy and light chain genes [2-4]. The Oct transcription factors, which bind octamer motifs, are members of the POU ( $\underline{\text { Pit, }}$ Oct, $\underline{U}$ nc) family of proteins which are characterized by a bipartite DNA binding domain. The binding domain consists of two subdomains, the POU specific $\left(\mathrm{POU}_{\mathrm{S}}\right)$ domain and the POU homeodomain $\left(\mathrm{POU}_{\mathrm{H}}\right)$ that are joined by a linker region, whose flexibility allows recognition of the cognate octamer motif by binding to both faces of the DNA $[5,6]$. The POU proteins can be grouped, based on the structure of their POU domains, into six or more classes $[7,8]$ POU transcription factors of Class II have been widely studied in the vertebrates, and members of this class have also been reported in ecdysozoan invertebrates such as Drosophila [9], and in the deuterostomate echinoderm Strongylocentrotus purpuratus [10], and the urochordate Oikopleura dioica [11]. In the vertebrates, Oct1 (which is ubiquitously expressed) and Oct2 (which is expressed predominantly in B cells and the central nervous system) are the most widely studied Class II POU transcription factors. Both Oct 1 and Oct 2 are essential transcription factors, with Oct1 gene knockout in mouse being embryonic lethal [12] and Oct2 knockout resulting in death shortly after birth [13].

While Oct1 is involved in directing the transcription of both Pol II and Pol III genes, Oct 2 was originally thought to have a more restricted role, for example in controlling IG gene transcription in B cells [14,15]. However, subsequent studies [13] suggested that Oct2 is redundant, because Oct1 can also play a significant role in the transcription of mammalian IG genes. Depletion studies in HeLa cells and BJA-B cells indicated that both Oct 1 and Oct 2 could drive transcription from the IGH promoter in either cell line and with nearly identical binding activity [16]. In order to explain the evidence that transcription of both ubiquitously expressed and cell type restricted genes could be regulated by Oct 1 or Oct 2 , the idea of a $\mathrm{B}$ cell specific co-activator arose. The discovery of BOB.1 (OBF1 or OCA-B), a B cell specific co-activator of Oct1 and Oct2 proteins, was thought to provide the answer [17-19]. However, thorough exploration of mouse $\mathrm{B}$ cell development and function in the absence of Oct1[20], Oct2 [13] or BOB.1[21], or a combination of Oct2 and BOB.1[22], showed surprisingly little effect on IGHM gene transcription. Some effects were noticed in the production of secondary isotypes (IGHG and IGHA) and in the formation of germinal centers. Thus, although the details of the mechanisms controlling the expression of $I G$ genes in mammalian B-cells remain unclear, neither Oct1 nor Oct2 are essential transcription factors for this function, and the potential for comparative studies to shed light on the essential and evolutionarily-conserved aspects of IG gene transcription is considerable.

The channel catfish provides a system for studying the transcriptional control of teleost IG genes, particularly with respect to the heavy chain (IGH) locus where octamer motifs and octamer-binding transcription factors have been shown to play important roles [23]. Catfish express only two classes of immunoglobulin (IGHM and IGHD) and class switching by chromosomal recombination is absent [24-26]. A single enhancer, E 43 ', has been found associated with the expressed IGHM1 and IGHD1 genes of the catfish $[27,28]$ and is situated immediately $3^{\prime}$ of the IGHM1 gene. The core region of this enhancer consists of two variant (but fully functional) octamer motifs and a $\mu \mathrm{E} 5$ site. It has been previously established that octamer-binding transcription factors are important in driving transcription from the catfish E $\mu 3$ ' enhancer [23]. This situation in the catfish differs from what is seen with the mammalian IGH locus, where the E $\mu$ enhancer is located 5' of the constant region gene cluster and contains a single octamer motif, which is not within the core enhancer [29,30]. Catfish Oct2 has been cloned and shown to be expressed as two predominant isoforms, Oct $2 \alpha$ and $\beta$, derived from a single gene by alternative RNA processing. Both catfish Oct 2 isoforms are transcriptionally active [31], although the $\beta$ isoform is a more potent transactivator than Oct $2 \alpha$ due to differences in the C-terminal proline, serine, threonine rich activation domains of the two isoforms [32]. While the role of catfish Oct2 in transcriptional control of the IGH locus of the channel catfish is well understood, the functional significance of other Oct transcription factors has not yet been determined. The study reported here was undertaken to clone the catfish orthologue of Oct1, and to characterize its expression and function in driving transcription of the IGH locus in B cells.

\section{Results \\ Identification of an Octl orthologue in channel catfish}

A cDNA library from a catfish monocyte cell line (42TA) was screened with a $32 \mathrm{P}$-labeled probe for the POU domain of catfish Oct2 (see Methods), and a full-length clone with putative homology to vertebrate Oct1 was identified. An amino acid sequence alignment of Oct1 genes can be found in Fig 1A. From the alignment a schematic of the inferred structure of catfish Oct1 was made and is shown in Fig $1 \mathrm{~B}$. The amino acid alignment confirmed the high level of conservation within the POU specific domain and the POU homeodomain (96\% and 78\% with the homologous mouse Oct1 domains, respectively). The putative activation domains $\mathrm{N}$ - and C-terminal to the 
A.

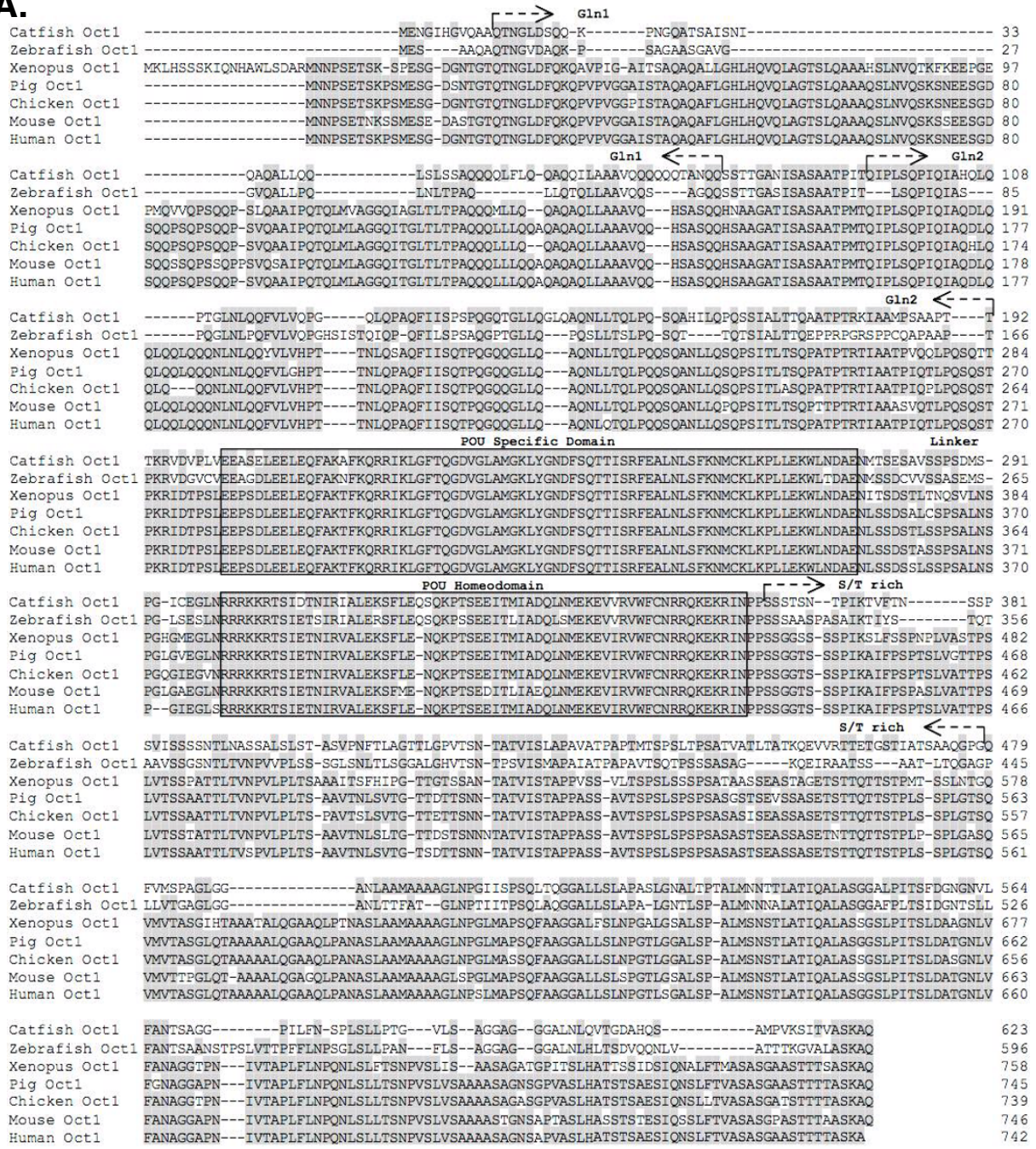

B.

Catfish Oct1

Zebrafish Oct1

Mouse Oct1

Mouse Oct2.1

Cattish Oct2 $\beta$
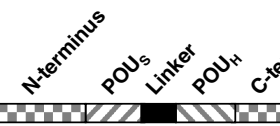

45
45
18
23

$\begin{array}{lll}94 & 62 & 90 \\ 96 & 37 & 78 \\ 94 & 25 & 7\end{array}$

$\begin{array}{llll}93 & 41 & 80 & 35\end{array}$
C.

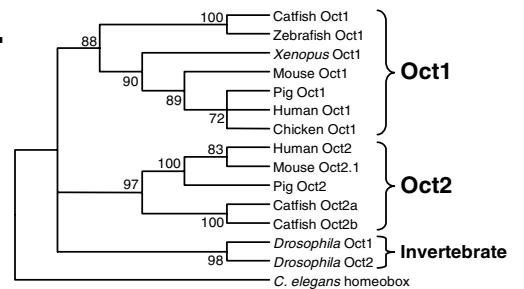

Figure I

An Oct I orthologue in catfish. A. Megalin (DNAStar) amino acid alignment of Octl proteins. Conserved residues are shaded by grey boxes. The boxed portion indicates the bipartite POU DNA binding domain. Glutamine rich regions are denoted by arrows and text GlnI or Gln2. Serine and thrionine rich residues are denoted by arrows and S/T rich. The linker region is also designated by text. Gaps in the sequence alignment are indicated by a dash. B. Schematic comparing the domain structure of Oct transcription factors. $\mathrm{N}$ - and $\mathrm{C}$ - terminal domains are shown as checkered boxes, POU domains are shown hatched with diagonal lines, and the linker region is shown as a black box. The percent identity values (derived using the Megalign program, DNAStar) are based on the amino acid sequences and are shown below the schematic. C. Neighbor joining phylogenetic tree [49] of Octl and Oct2 transcription factor sequences (see Methods). The $C$. elegans homeobox gene was used as the outgroup. The three branches for Octl, Oct2 and the invertebrate Oct sequences are indicated by brackets, and the bootstrap value for each node is shown. 


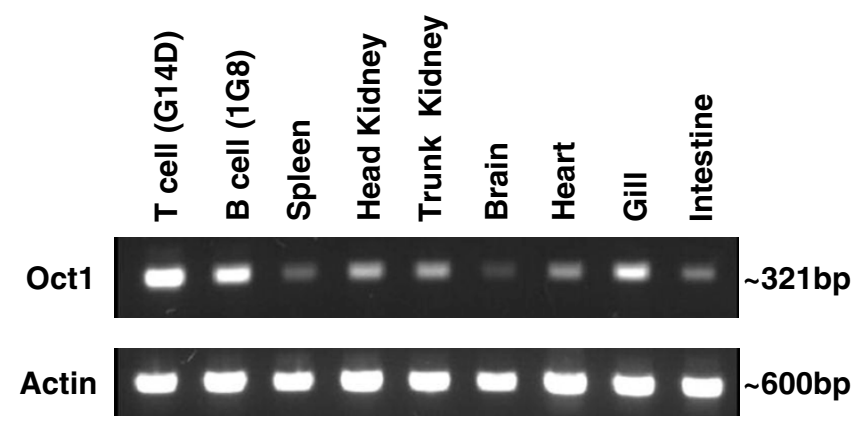

Figure 2

Catfish Oct I is widely expressed. RNA was isolated from the catfish T cell line (GI4D) and B cell line (IG8) as well as catfish tissues (spleen, head kidney, trunk kidney, brain, heart, gill, and intestine) and subjected to RT-PCR analysis to detect Oct l (top panel), as described in the Methods section. RT-PCR detection of the catfish actin transcript is shown in the bottom panel.

POU domain also showed substantial sequence identity, ranging between $36 \%$ and $46 \%$ in comparison with the mouse and zebrafish Oct1 activation domains. A more comprehensive analysis of the evolutionary relationships of catfish Oct1 is shown in the phylogenetic tree of Fig 1C. This demonstrates that the separation into Oct 1 and Oct2 occurred early in vertebrate evolution, and that the invertebrate Oct genes form an outgroup and cannot be classified clearly as either Oct1 or Oct2 othologues [33]. Although isoforms of catfish Oct2 have easily been identified [31], analysis by RT-PCR and RACE-PCR of cDNA from catfish B cell and T cell lines (see Methods) did not identify any sequences of catfish Oct1 other than the one originally isolated (Fig 1).

\section{Catfish Octl is widely expressed}

Ubiquitous expression in cells and tissues is one of the key features that distinguishes mammalian Oct 1 from the tissue-restricted Oct2. Therefore, the expression of catfish Oct1 in clonal T and B cell lines and in a variety of tissues was analyzed by RT-PCR (Fig 2). The primers used in the RT- PCR analysis were designed within the C-terminus of the catfish Oct1 to distinguish the Oct1 gene from the two isoforms of catfish Oct2. The primer sequences were not found within the sequence for either isoform of catfish Oct2 and NCBI blast search returned matches only to the catfish Oct1 sequence. The cloned, catfish $\mathrm{B}$ and $\mathrm{T}$ cell lines both expressed Oct1, as did all of the tissues examined, including spleen, head and trunk kidney, brain, heart, gill and intestine. This pattern of widespread expres- sion is consistent with its mammalian counterparts, and with the expectation that it would play a significant role in gene regulation. Thus, the ability of catfish Oct1 to drive expression from a variety of octamer-containing reporter constructs was tested.

\section{Transcriptional Activity of catfish Oct I}

An Oct 1 expression vector was co-transfected, with several different reporter constructs, all of which contained octamer motifs, into catfish B cell lines. Oct1 was, surprisingly, unable to drive transcription from an octamerdependent reporter that contains a trimer of octamer motifs upstream of a minimal $c$-fos promoter, and which is responsive to catfish Oct2 (Fig 3A). Whilst the transcription driven by the transfected Oct 1 was actually found to be significantly suppressive $(\mathrm{p}<.01)$ from the empty vector control, catfish Oct2, as predicted, induced transcription strongly. We considered the possibility that Oct1 requires a co-activator to function, and thus examined its ability to act in concert with human BOB.1, a co-activator of Oct transcription factors. BOB.1 has previously been shown to activate transcription synergistically with catfish Oct2 [34] but as shown in Fig 3B, human BOB.1 was unable to act synergistically with catfish Oct1. This was not due to a lack of function of BOB.1, as it enhanced transcription (at a statistically significant level) from the octamer-dependent reporter when transfected alone into catfish B cells, presumably through interaction with the endogenous Oct transcription factors. The interaction of human BOB.1 with catfish Oct2 gave transcription that was increased above the level seen with either BOB.1 or Oct2 transfected alone (Fig 3B). Whilst this interactive effect of BOB.1 on Oct2-driven transcription did not reach statistical significance $(p<0.07)$, in a second series of experiments (described below) this effect was confirmed (see Fig 4B). The possibility that catfish Oct1 and Oct2 might act synergistically was tested in a series of co-transfection experiments. The results (Fig 3C) showed that the transcriptional activation produced by catfish Oct2 was in fact reduced (in a statistically significant manner) with increasing amounts of co-transfected Oct1. In order to test if the inability of catfish Oct1 to drive transcription was reporter-dependent, its activity was tested on two other physiologically-relevant reporter constructs. The ability of catfish Oct1 to drive transcription from a reporter construct containing a minimal promoter and the core region of the enhancer (E $\left.\mu 3^{\prime}\right)$ of the catfish IGH locus was tested in both mouse J558L plasmacytoma cells and in the catfish $\mathrm{B}$ cell line 1G8. The results show that this reporter, while responsive to catfish Oct2, was unresponsive to Oct1 both in mouse (Fig 4A) and catfish (Fig 4B) cells. The activation by catfish Oct 2 was statistically significant (when compared to the reporter construct alone) activation by catfish Oct1 was not. When catfish Oct1 and human ВОВ.1 were co-transfected, the level of transcrip- 


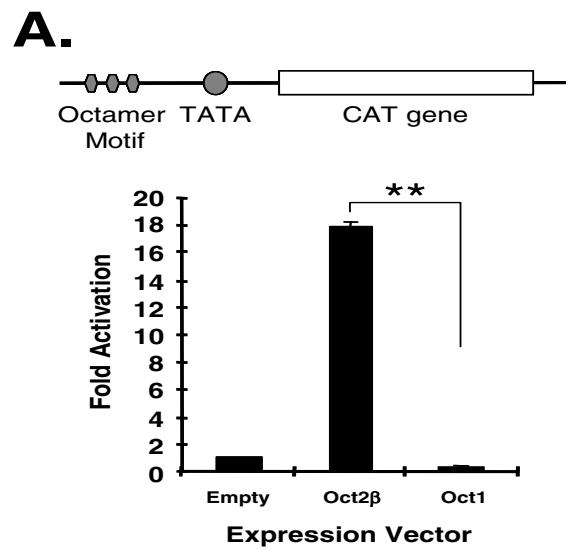

B.
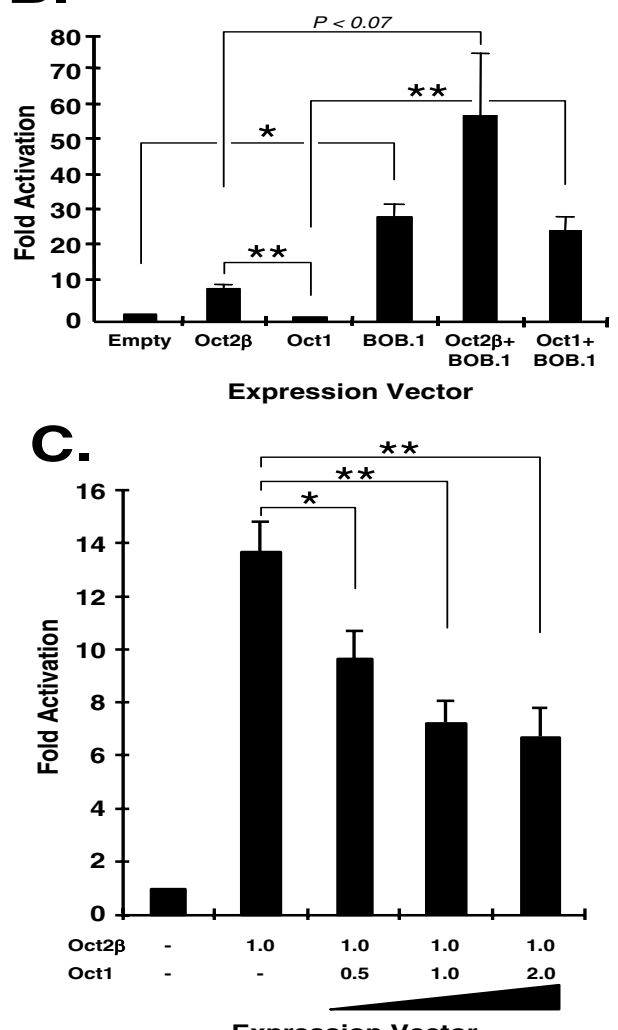

Expression Vector

\section{Figure 3}

Catfish Oct I fails to drive transcription from an octamer-dependent reporter construct. A schematic representation of the reporter construct ( $\mathrm{pO} 3-\Delta 56-\mathrm{CAT}[3 \mathrm{I}]$ ) containing an octamer trimer is shown in $\mathrm{A}$. The octamer motifs are shown upstream of the TATA box (from the minimal c-fos promoter) and the CAT reporter gene is shown as an open box. Transcriptional activation (as fold increase) was measured following co-transfection into the catfish B cell line (IG8) of the reporter construct and an Oct expression construct. A. Transcriptional activation driven by catfish Oct $2 \beta$ (pRc/CMV/Oct $2 \beta$ ) or catfish Octl (pRc/CMV/Octl). B. Transcriptional activation driven by catfish Oct2 3 (pRc/CMV/Oct2 2 ), catfish Octl (pRcl $\mathrm{CMV} / \mathrm{Octl}$ ) and human BOB.I (pRc/CMV/hBOB.I), or by a co-transfection of catfish Oct2 $\beta$ with human BOB.I, or catfish Oct I with human BOB.I. C. Negative transcriptional regulation by catfish Octl. One pM of catfish Oct $2 \beta$ expression construct was co-transfected with increasing amounts of catfish Octl $(0.5,1.0,2.0 \mathrm{pM}$ respectively) and the transcriptional activation of the reporter construct measured. Values for five replicate transfections in $A$ and four replicate transfections in $B$ and $C$ are shown as mean \pm SEM. Statistical significance was calculated by the Student $T$ test assuming unequal variances. One asterisk indicates a $\mathrm{p}$ value of less than .05 and two asterisks indicates a $\mathrm{P}$ value of less than $.0 \mathrm{l}$. 

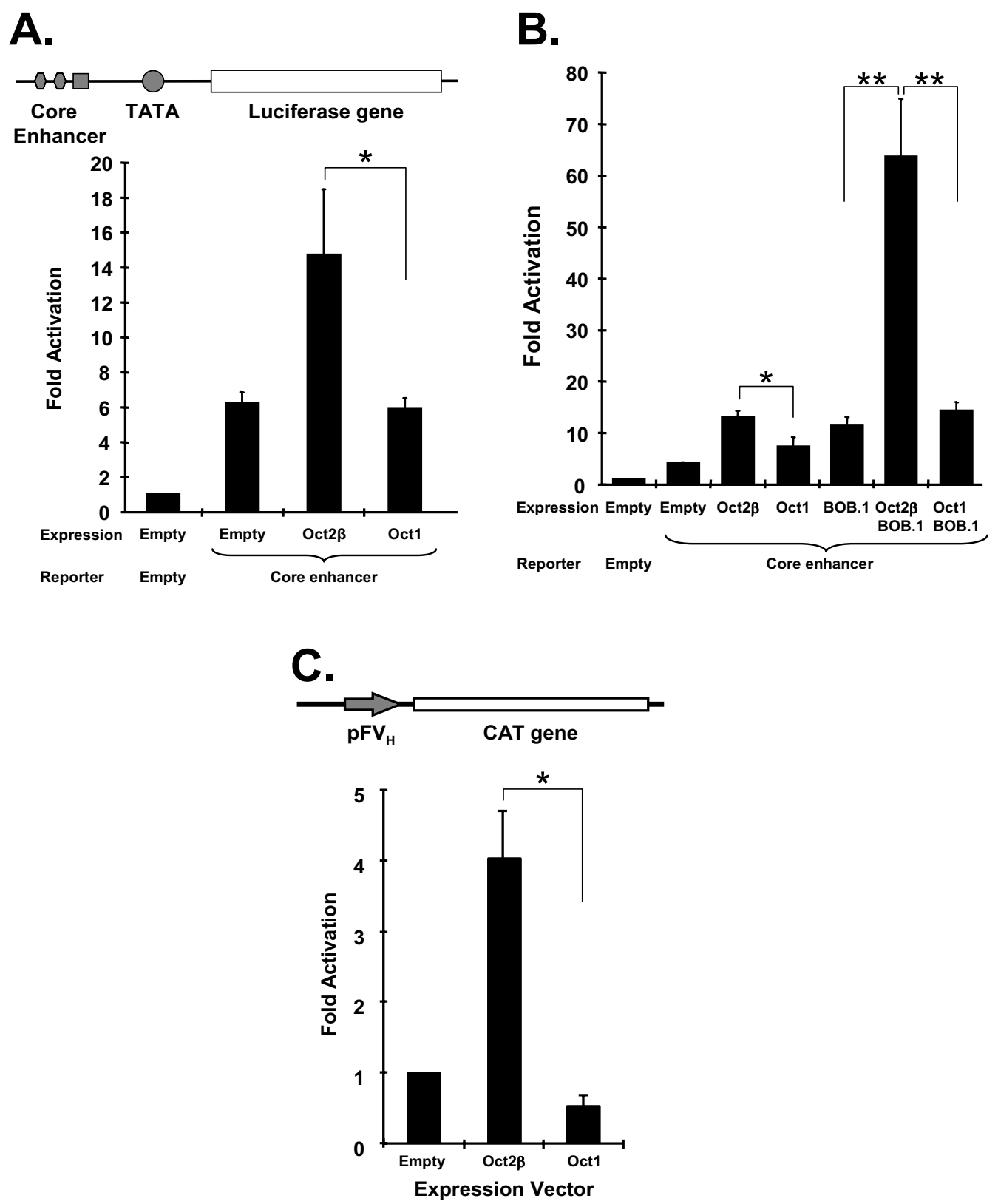

Figure 4

Catfish Oct I fails to drive transcription from physiologically relevant reporter constructs. A. Schematic diagram of the reporter construct $p G L 3 / \Delta 56 / R \# 2$ [50]. This contains the core of the catfish enhancer in which there are 2 octamer motifs (ovals) and a $\mu \mathrm{E} 5$ site (square) upstream of a minimal TATA box (circle) followed by the luciferase gene (open rectangle). This reporter construct was used in the experiments shown in panels A\&B. A. Transcriptional activation driven from the core enhancer by catfish Oct2 $\beta$ (pRc/CMV/Oct2 $\beta$ ) or catfish Octl (pRc/CMV/Octl) in the mouse B cell line (J558L). B. Transcriptional activation in the catfish B cell line IG8 driven from the core enhancer construct by catfish Oct2 $\beta$ ( $p$ Rc/CMV/ Oct2 $\beta$ ), catfish Octl (pRc/CMV/Octl), human BOB.I (pRc/CMV/hBOB.I), or by a co-transfection of catfish Oct2 $\beta$ with human BOB.I, or catfish Octl with human BOB.I. C. (Top) Schematic diagram of the reporter construct (pFVH-CAT) that contains a full fish $V_{H}$ promoter (arrow) followed by the CAT gene [27]. C. (Bottom) Transcriptional activation driven from the $V_{H}$ promoter (pFVH-CAT) by catfish Oct2 $\beta$ (pRc/CMV/Oct2 $\beta$ ) or catfish Octl (pRc/CMV/Octl) co-transfected with the reporter construct into catfish IG8 B cells. Values are presented as mean \pm SD for 12 replicates (A), 9 replicates (B), and 4 replicates (C). Statistical significance was calculated by the Student $T$ test assuming unequal variances. One asterisk indicates a $P$ value of less than .05 and two asterisks indicate a $\mathrm{p}$ value of less than $.0 \mathrm{I}$. 


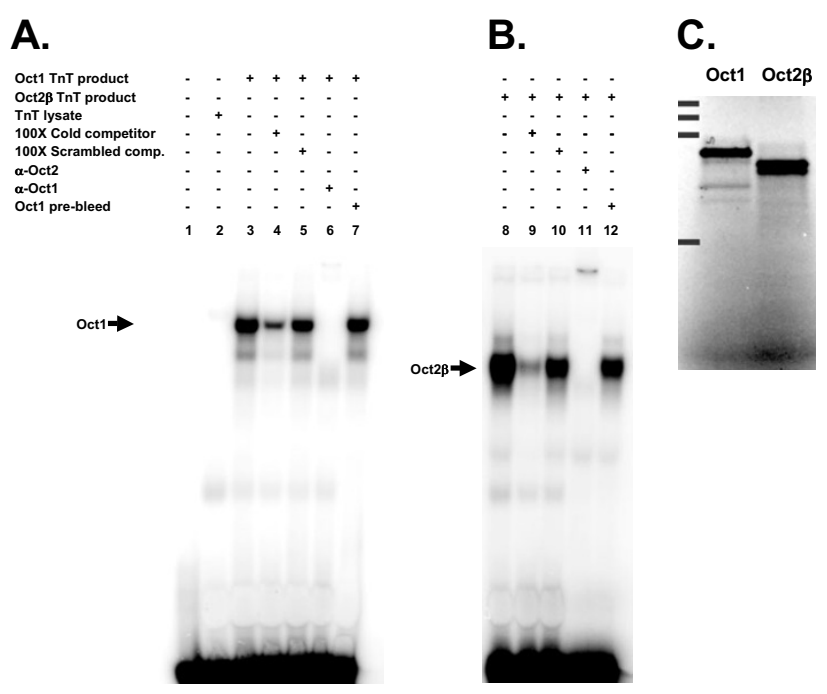

Figure 5

In vitro transcribed Oct transcription factors bind the octamer motif. A. EMSA demonstrating the binding of catfish Octl to the first octamer motif within the core enhancer. Lane I, free probe. Lane 2, TNT reaction without template DNA (control). Lane 3, catfish Oct I TNT product. Lane 4, catfish Oct I TNT product + cold competitor. Lane 5, catfish Oct I TNT product + scrambled competitor. Lane 6, catfish Oct I TNT product + anti-Octl rabbit serum. Lane 7, catfish Octl TNT product + NRS (anti-Octl rabbit prebleed serum). Arrow depicts the Octl shift. B. EMSA demonstrating the binding of catfish Oct2 $\beta$ to the first octamer motif within the core enhancer. Lane I, catfish Oct2 $\beta$ TNT product. Lane 2 , catfish Oct $2 \beta$ TNT product + cold competitor. Lane 3, catfish Oct2 $\beta$ TNT product + scrambled competitor. Lane 4, catfish Oct2 $\beta$ TNT product + anti-Oct2 $\beta$ rabbit serum. Lane 5 , catfish Oct $2 \beta$ TNT product + NRS (anti-Octl rabbit pre-bleed serum. C. Detection of ${ }^{35} \mathrm{~S}$ labeled TNT transcribed and translated Oct I and Oct2 $\beta$ by SDS-PAGE and phosphor imaging. Solid black bands on the left hand side represent the kaleidoscope protein marker (Bio-Rad, Hercules, CA.), 222kDa, $129 \mathrm{kDa}, 83 \mathrm{kDa}, 43 \mathrm{kDa}$ (from top to bottom).

tional activation was no higher than that seen with BOB.1 alone (Fig 4B), confirming the inability of catfish Oct1 to interact positively with this co-activator. Co-transfection of human BOB.1 with catfish Oct2 enhanced transcription to a statistically significant extent, supporting the effect suggested by the results shown in Fig 3B. The activity of catfish Oct1 was then tested with a third octamer-containing reporter construct, in which expression is driven from a fish $V_{H}$ gene promoter that contains a single octamer motif (Fig 4C). While this construct was highly responsive to Oct2, it failed to respond to co-transfected Oct1 (Fig 4C) and these results were also found to be statistically significant. Given these unexpected results, the possibilities were next considered that catfish Oct1 was either a) unable to bind to an octamer motif or b) if it could bind to an octamer motif, it lacked functional activation domains.

In vitro expressed catfish Oct I binds the octamer motif In order to test the ability of catfish Oct1 to bind to the octamer motif, catfish Oct $2 \beta$ and catfish Oct 1 proteins were produced by in vitro transcription and translation and tested by EMSA for their ability to bind the native octamer motif (ATGtAAAT) found within the catfish core enhancer (Fig 5). The first two lanes of the gel shift show the free probe (Fig 5A, Lane 1) and the TNT lysate (Fig 5A, Lane 2) without the addition of any DNA as controls. These results show that Oct1 bound to the octamer motif (Fig 5A, Lane 3), and that the binding was specifically inhibited by an excess of unlabeled octamer motif (Fig 5A, Lane 4) but not by an excess of the octamer sequence that had been scrambled (Fig 5A, Lane 5). Addition of the antibody to catfish Oct1 eliminated the shifted band (Fig 5A, Lane 6), indicating that the observed shift was Oct1induced. The control (preimmunization bleed) serum did not affect the observed shift (Fig 5A, Lane 7). The ability of catfish Oct $2 \beta$ to bind to the native octamer motif was confirmed by the results (shown in Fig 5B) which are similar to those observed with catfish Oct1. The in vitro synthesized proteins were checked for size by radiolabeling with ${ }^{35} \mathrm{~S}$ methionine and analyzed on an SDS PAGE gel (figure $5 \mathrm{C}$ ). The sizes of the protein bands produced for catfish Oct 1 and Oct $2 \beta$ were consistent with the expected sizes of the proteins, $65 \mathrm{kDa}$ for catfish Oct 1 and $52 \mathrm{kDa}$ for catfish Oct $2 \beta$.

\section{Octamer-binding transcription factors of catfish B cells}

The ability of endogenous transcription factors expressed in catfish B cells to bind the octamer motif was also tested by EMSA. Nuclear extracts from the catfish 1G8 B cell line generated complex patterns of shifted bands when tested with a consensus octamer motif (Fig 6, Lane 1). However, all the shifted bands were abolished by an excess of unlabeled octamer motif (Fig 6, Lane 2), but not by the addition of a scrambled octamer motif (Fig 6, Lane 3) and interpretation of the banding pattern was made possible using antisera specific to Oct1 and to Oct2. The uppermost shifted band is clearly attributable to Oct1, as seen from the supershift of this band in the presence of antibody to Oct1 (Fig 6, Lanes 6, 7). Below this Oct1 shift is an envelope of strong bands attributable to Oct2, as evidenced by their supershift with antibody to Oct2 (Fig 6, Lanes 4,7$)$. Antibody to Oct2 failed to supershift a faint band within this lower Oct2 envelope, but the combination of antibody to Oct1 and to Oct2 supershifted all bands in the upper region of the gel (Fig 6, Lane 7). The nature of the lower, diffuse bands observed in the EMSA is not known, but they were not supershifted by the antibodies to either Oct1 or Oct2 (Fig 6, Lanes 4-7). 


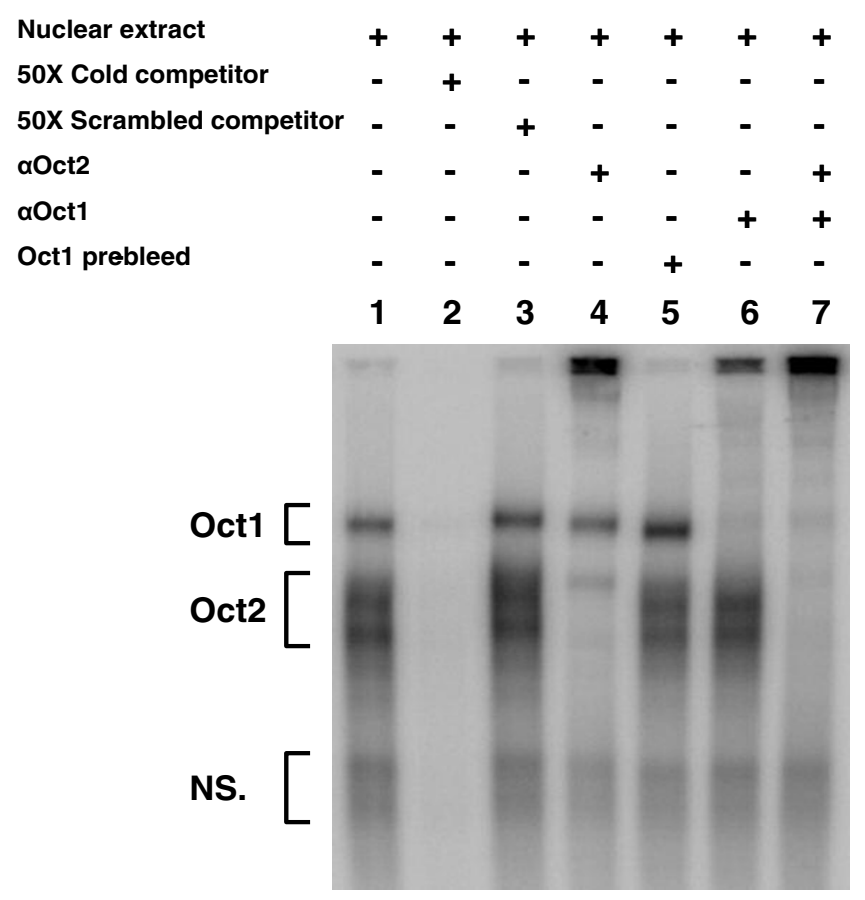

\section{Figure 6}

\section{Endogenous Oct transcription factors bind the} octamer motif. EMSA with nuclear extracts of the catfish $B$ cell line IG8. Lane I, nuclear extract. Lane 2, nuclear extract + cold competitor. Lane 3, nuclear extract + scrambled competitor. Lane 4, nuclear extract + anti-Oct2 rabbit serum. Lane 5, nuclear extract + NRS (anti-Octl rabbit pre-bleed serum. Lane 6, nuclear extract + anti-Octl rabbit serum. Lane 7, nuclear extract + anti-Octl rabbit serum + anti-Oct2 rabbit serum. Octl and Oct2 shifts are designated by brackets. A lower bracket designates non specific binding labeled NS.

\section{Catfish Oct I lacks functional activation domains}

The above results clearly demonstrate that catfish Oct 1 is capable of binding to the octamer motif. Thus, in order to address the failure of catfish Oct 1 to activate transcription, the function of the $\mathrm{N}$ - and C-terminal putative activation domains was tested. Expression constructs containing the Gal4 DNA binding domain fused to Oct1 and Oct2 putative activation domains were generated, and tested by cotransfection with a reporter constructs containing Gal4 binding sites in the promoter region (Fig 7A, B). These constructs were co-transfected into catfish B cells (the 1G8 cell line) and their ability to drive transcription from the reporter construct is shown in Table 1 . The negative con- trols (Gal4 binding domain fused to nucleolin or to the Oct1 POU domain) were inactive or suppressive, whereas the positive control (Gal4 binding domain fused to the VP16 activation domain) showed strong statistically significant activity. The C-terminal domain of the catfish Oct $2 \beta$ isoform was also strongly active and statistically significant, giving a greater than 300 -fold stimulation of expression. There was low activation (3-fold) seen with the N-terminus of catfish Oct $2 \beta$; this level of activity is consistent with what has previously been reported and nearly statistically significant with a p-value of .057[32]. However, in the case of catfish Oct1, both the C-terminal and N-terminal domains are lacking in substantial activation ability (Table 1). While there was a slight activation (2-fold) with the $\mathrm{C}$ terminal domain, this activation was negligible and not statistically significant when compared to that of the catfish Oct $2 \beta$ C-terminus. In the case of the $\mathrm{N}$-terminal domain of Oct1, it suppressed rather than enhanced transcription, this suppression was also seen to be significant from the DNA binding domain alone. Examination of the Oct 1 sequence alignment in Figure 1 shows the lack of several gln residues known to be important in the N-terminal activation domain of mammalian Oct1 $[14,37,38]$. Within the Gln1 region (Fig. 1A), which is located in the human Oct 1 sequence from amino acid $22-145,52 \%$ of the gln residues found in the human sequence are missing in catfish Oct 1 and $68 \%$ are missing in the zebrafish Oct 1 sequence. In the Gln2 region (amino acid 163-268 in human Oct1), 42\% of the gln residues are missing in the catfish and 58\% are missing in the zebrafish Oct1. The absence of these gln residues suggests that teleost Oct1 may not possess the capability to act as a transcriptional regulator. Further examination of the ser/ thr rich region $[14,37]$ located from amino acid 441-560 in human Oct1 indicates a similar pattern, i.e. $67 \%$ and $69 \%$ of ser and thr residues present in the human sequence are absent in the homologous regions of catfish and zebrafish Oct1, respectively.

\section{Discussion}

The conclusion that the cloned catfish molecule identified in this study is a homologue of Oct 1 is supported by 4 observations. First, it shows well-conserved sequence similarity to other vertebrate Oct1 (especially in the POU domain); secondly, in phylogenetic analyses it clusters to the same tree branch as other vertebrate Oct1 sequences; thirdly, it binds the octamer DNA sequence motif; and fourthly, it shows the widespread pattern of expression characteristic of vertebrate Oct1. In human and mouse several isoforms of Oct1 have been isolated, arising from alternative splicing involving the 21 expressed exons of this gene, [35]. In contrast, examination of catfish macrophage and B cell lines by RT-PCR and RACE failed to identify any alternatively spliced isoforms of catfish Oct1. However, EMSA analysis of endogenous octamer-binding 
transcription factors (Fig 6) suggested the possibility that an additional minor isoform of Oct1 might be expressed in catfish B cells. It is possible a) that an Oct1 isoform may be expressed at such a low level that the technique used may have failed to detect its presence or $b$ ) the primers designed for this study may have been placed in exons not included in the transcript. Analysis of the teleost fish genomes currently being sequenced revealed orthologues of the Oct1 in the zebrafish Danio rerio, (ENSDARG00000007996), the puffer fishes Takifugu rubripes (NEWSINFRUG00000159819) and Tetraodon nigroviridis (GSTENG00025967001), and the three-spined stickleback Gasterosteus aculeatus (ENSGACG00000003150). Interestingly, in only one of these species, the stickleback is Oct1 reported to have more than one transcript. Thus, despite the whole genome duplication that occurred in teleost fishes, to date no evidence for more than a single Oct1 gene has been found. While it is likely that only one Oct1 gene exists in the teleost fishes (including catfish) this question will not be resolved until the sequencing and assembly of the teleost genome sequences is completed

Although orthologues of Oct 1 are present in the genomes of four other teleost fish this study represents the first examination of the function of a teleost Oct 1 orthologue. Contrary to our expectations, catfish Oct 1 was clearly unable to activate transcription, even though it binds to the octamer motif. This inability to drive transcription was seen using three different octamer-containing reporter constructs transfected into both mouse and catfish B cells. Not only did the catfish Oct 1 fail to activate transcription from a reporter construct with a synthetic trimer of octamer motifs in the promoter region, but it also failed to activate transcription from two constructs driven by physiologically-relevant octamer-containing elements; in one case a complete fish $V_{H}$ promoter [36], and in the other case the core region of the $\mathrm{E} \mu 3^{\prime}$ enhancer of the channel catfish IGH locus [23]. In all cases, while the catfish Oct2 drove transcription from the reporter constructs to a statistically significant level, catfish Oct1 did not. Binding of both native and in vitro expressed catfish Oct1 was shown with both the consensus octamer motif (ATGCAAAT) or the variant octamer motif (ATGtAAAT) located within the core region of the catfish enhancer E $\mu 3$ '. To dissect the molecular basis for the lack of transcriptional activation of catfish Oct1, a Gal4 fusion study of the putative activation domains was undertaken. The results of this study clearly demonstrate the lack of activity of the putative activation domains in both the $\mathrm{N}$ - and Cterminus of the catfish Oct1 possibly associated with the relative lack of residues known to be associated with activation domain function, i.e. gln residues in the $\mathrm{N}$-terminal domain and ser and thr residues in the C-terminal domain of catfish Oct 1. Co-transfection studies involving catfish Oct 1 and Oct 2 suggested that catfish Oct 1 could be a negative regulator of transcription, in that it significantly inhibited activation driven by Oct2. The mammalian coactivator BOB. 1 has been shown to act synergistically with both mammalian Oct 1 and Oct 2 to drive transcription [19], and the possibility was considered that this co-activator might rescue the activation function of catfish Oct 1 . However, while co-transfection studies confirmed that human BOB.1 is capable of significantly enhancing transcriptional activation driven by catfish Oct $2 \beta$ (Figures 3 and 4 and [34]), BOB.1 did not confer transcriptional activation ability on catfish Oct1. The failure of BOB.1 and catfish Oct1 to function in a synergistic manner could result from impaired physical interaction between BOB.1 and catfish Oct1. However, the BOB.1/Oct interaction is through the Oct POU domain [39] which is the most highly conserved region of the catfish Oct1 molecule (Fig 1). All of the residues in the mammalian Oct1 POU domains that are known to interact with BOB.1, including Leu6, Glu7, Leu9, Glu10, Leu53, Asn54, Phe57, Met60 within the $\mathrm{POU}_{\mathrm{S}}$ domain and Lys55, Arg58, Ile59 within the $\mathrm{POU}_{\mathrm{H}}$ domain [39] are conserved in catfish Oct1. This suggests the possibility that catfish Oct 1 might function in concert with endogenous co-activators, such as a catfish homologue of BOB.1. However, if this were the case, transcriptional activation by Oct 1 expressing constructs transfected into catfish B cells would have been predicted. These results suggest, collectively, a potential mechanism of transcriptional control in the catfish IGH locus whereby Oct 1, as a negative regulator of transcription and Oct2, as an activator of transcription compete for binding to the octamer motifs found within the intronic enhancer (E $\left.\mu 33^{\prime}\right)$ and the $V_{H}$ promoters $[27,40]$.

Mammalian Oct1 is involved in driving transcription from both Pol II and Pol III promoters and also has a role in recruiting basal transcription factors such as SNAPC [41]. In addition, mammalian Oct1 demonstrates promoter-selective activation domains and its ability to drive mRNA transcription can be weaker than that of Oct2 $[14,42,43]$. While mammalian Oct1 has not been reported to act as a negative regulator of IG gene transcription, its very diverse functions in regulating the expression of other genes include both positive and negative effects. In the case of the Gonadotropin-Releasing Hormone Receptor (GnRHR) gene, Oct1 has been shown to be capable of both activation and repression [44]. The POU domain of Oct1 interacts with the silencing mediator for retinoid and thyroid receptors (SMRT), recruiting histone deacetylases to the promoter and leading to transcriptional repression [45]. Two more recent studies have indicated additional roles for Oct1. Mouse embryo fibroblast (MEF) cell lines depleted of Oct1 showed an arrest in Herpes simplex virus replication, due to a role for Oct 1 in aiding viral assembly as well as a likely secondary role 


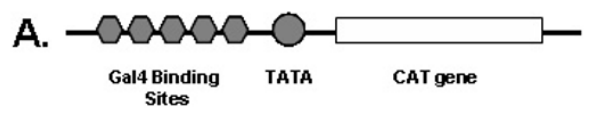

B. Effector Constructs

\begin{tabular}{|c|c|c|}
\hline \multirow[t]{2}{*}{ Gal4 DBD } & $\begin{array}{l}\text { Activation } \\
\text { Domain }\end{array}$ & \multirow[b]{2}{*}{ Oct1 Pou Domain } \\
\hline & & \\
\hline & 典曲曲曲曲 & Oct1 N-Term \\
\hline & 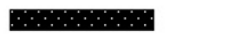 & Oct1 C-Term \\
\hline & \#IIIA & VP16 \\
\hline & 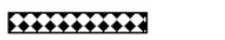 & Oct2 $\beta$ N-Term \\
\hline & 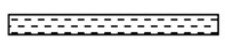 & Oct2 $\beta$ C-Term \\
\hline & 空空 & Nucleolin \\
\hline & - & No Act. Domain \\
\hline
\end{tabular}

\section{Figure 7}

Schematic of Gal4 fusion proteins. A. Depicts the pG5/ CAT reporter construct. Gal4 binding sites (grey hexagons), TATA promoter (grey circle) and the CAT gene (open rectangle). A schematic of the effector constructs used in B. CMV promoter (black arrow), Gal4 DNA binding domain (black rectangle), Octl POU domain (grey rectangle), Oct I $\mathrm{N}$-terminus (plaid rectangle), Oct I C-terminus (black with white dotted rectangle), VPI6 (diagonal stripped rectangle), Oct2 $\beta$ N-terminus (black diamond rectangle), Oct2 $\beta$ C-terminus (white with black dotted rectangle), Nucleolin (tire track rectangle), empty activation domain (dotted line).

affecting viral DNA replication [46]. A recent study of gene expression has also indicated that Oct1 can act as a stress sensor. Mouse fibroblasts deficient in Oct1 showed altered expression in a variety of genes known to be involved in the response to oxidative and metabolical stress [47]. In both of these cases the DNA binding ability of Oct1 is critical.

\section{Conclusion}

The study reported here is the first demonstration that an Oct1 protein has an inhibitory effect on the transcriptional regulatory elements of $I G$ genes. However, given that mammalian Oct1 has multiple and diverse roles, it is possible that Oct1 in teleosts has significantly different roles from those seen in mammals, relating not only to the transcription of genes but to the response to cellular stress and viral infection.

\section{Methods}

Cloning and Sequence Determination of Catfish Oct I

A cDNA library was prepared in $\lambda$ ZAPII (Stratagene, La Jolla, CA) from the 42TA catfish monocyte/macrophage line [48]. Approximately $2.5 \times 10^{5}$ pfu were screened at high stringency with a $32 \mathrm{P}$-labeled probe to the POU domain of catfish Oct2 [31]. Two positive clones were obtained and plaque purified. One of these contained a full-length Oct1, and its sequence (GenBank Acc\#AJ000267) was determined from both strands by primer-extension sequencing (Biomolecular Resource Laboratory of the Medical University of South Carolina). Isoforms of Oct 1 were sought by 3'-RACE using forward primers at positions 1-21 (G-1594); 540-569(G-2338); 547-567 (G-1595); 943-966 (G-2335); 1063-1083 (G1596); 1836-1856 (G-1597), by 5'-RACE using reverse primers at positions 963-986 (G-2336); 1169-1195 (G2337 ) and by RT-PCR using these primers in appropriate combination with reverse downstream primers at positions 615-635 (G-1598); 1206-1226 (G-1599) and 1836-1856 (G-1600). An additional reverse primer in the 3'UTR of the Oct1 clone, G-1593 (5'-AATAAAGTCTAAAGAGCGAGG-3') was also used.

\section{Phylogenetic Analysis}

Sequence alignments were carried out using Clustal V in the Megalign suite of programs (DNA Star, Madison, WI) with PAM 250, gap length penalty of 10 and gap penalty of 10. Phylogenetic and molecular evolutionary analyses were conducted using MEGA version 2.1 [49]. The neighbor joining (NJ) phylogenetic tree of Oct1 full-length amino acid sequences was generated with 1000 bootstrap replications. The following amino acid sequences (accession numbers) were used to generate the NJ tree. Catfish Oct2 $\alpha$ (Y12651), Catfish Oct2 $\beta$ (Y12652), Catfish Oct1 (AJ00267), Human Oct2 (X13810), Human Oct1 (X13403), Pig Oct2 (Q29013), Pig Oct1 (L38524), Mouse Oct2.1 (X57936), Mouse Oct1 (X68363), Chicken Oct1 (M29972), Xenopus Oct1 (X57165), Zebrafish Oct1 (NM131438), Drosophila Oct2 (S80561), Drosophila Oct1 (S80559), and the Caenorhabditis. elegans homeobox protein (Z79757).

\section{RT-PCR}

Total RNA was isolated from the head kidney, trunk kidney, spleen, brain, heart, gill and intestine from catfish and from the B lymphoblastoid cell line (1G8) and the Tcell lines (G14D) of the catfish using Trizol (Invitrogen Life Technologies, San Diego, CA). The RNA was then treated with DNase I by addition to RNAeasy mini-kit columns (Qiagen, Valencia, CA). After elution from the columns $0.5 \mu \mathrm{L}$ of ribonuclease inhibitor, $40 \mathrm{u} / \mu \mathrm{l}$ (RNasin, Promega, Madison, WI), was added to the RNA. First strand synthesis was then completed using $4 \mu \mathrm{L}$ of total RNA, an oligo dT primer, and PowerScript Reverse Transcriptase (BD Biosciences Clontech, Palo Alto, CA). The concentration of cDNA was measured and diluted to $1 \mu \mathrm{g} /$ $\mu \mathrm{L}$. A final concentration of $4 \mathrm{ng} / \mu \mathrm{L}$ was used in the PCR reaction with Ex Taq polymerase (Takara, Shiga, Japan). The PCR program was performed for 30 cycles and used 
Table I: Lack of Activation from Catfish Octl.

\begin{tabular}{|c|c|c|c|}
\hline Activation Domain & Fold Activation & SE & $M$ \\
\hline No Activation Domain & 1.00 & 0.00 & \\
\hline VPI6 & 15505.00 & 2348.00 & $* *$ \\
\hline Nucleolin & 0.63 & 0.25 & \\
\hline Oct2 $\beta N$-terminus & 3.00 & 0.80 & $p=.057$ \\
\hline Oct2 $\beta$ C-terminus & 333.00 & 92.00 & $*$ \\
\hline Octl POU Domain & 0.35 & 0.46 & \\
\hline Octl N-terminus & -0.25 & 0.33 & $*$ \\
\hline Octl C-terminus & 2.00 & 1.21 & \\
\hline
\end{tabular}

Results reported for the activation of Gal4 fusion proteins as fold activation from background (no activation domain). SEM - Standard Error of the Mean calculated for six replicates. Statistical significance was calculated by the Student $T$ test assuming unequal variances. One asterisk indicates a $P$ value of less than .05 and two asterisks indicate a $p$ value of less than .01 .

the following profile: $30 \mathrm{sec}$ at $95^{\circ} \mathrm{C} ; 30 \mathrm{sec}$ at $55^{\circ} \mathrm{C} ; 2$ min at $72^{\circ} \mathrm{C}$. The following primers, located within the Cterminus of the Oct1 gene, were used in the RT-PCR analysis.

Primers:

For Oct1

G-1392 - 5' CGT CGC TTA CTC CCT CTG CTA C 3'

G-2890 - 5' GAT GCA AGA GCC TGA ATA GTG 3'

For Actin

G-1480 - 5' CCC ACA CTG TGC CCA TCT ATG A 3'

G-1481 - 5' GAC AGG GAG CCC AGG ATT GAG 3'

\section{Reporter Constructs and Expression Vectors}

Three octamer dependent reporter constructs were used. 1) a luciferase expressing construct, pGL3/ $\Delta 56 / R \# 2$, which contains the core region of the catfish E $\mu 3^{\prime}$ enhancer upstream of the minimal $c$-fos promoter (described in [50], 2) a chloramphenicol acetyltransferase expressing reporter, pO3- $\Delta 56$-CAT, with a trimer of octamer motifs (ATGCAAAT) upstream of the minimal $c$ fos promoter [31], and 3) a chloramphenicol acetyltransferase expressing reporter, pFVH-CAT, with a complete goldfish VH gene promoter [36]. The catfish Oct $2 \beta$ expression vector has been previously described [31]. The catfish Oct1 was directionally cloned (using NotI and ApaI sites) into the pRc/CMV expression vector. Coding sequences were amplified by PCR (forward primer G-2203 - 5' AAG GAA AAA AGC GGC CGC GGC ACC ATG GAG AAT GGA ATA CAT GGA GTC C 3', reverse primer G-2179 - 5' TTT GGG CCC TCA TTG CGC CTT GGA GGC CTC 3'). The restriction sites are underlined and a Kozak consensus sequence is shown in bold in the sense primer. The human BOB.1 vector, expressed from pRc/CMV, was a generous gift from P. Matthias (Friedrich Miescher Institute for Biomedical Research, Novartis Forschungsstiftung, Basel, Switzerland).

For the Gal4 fusion study the reporter construct pG5/CAT was used [32]. This construct contains 5 Gal4 binding sites, located upstream of a minimal TATA box promoter and the CAT reporter gene. The expression constructs for the fusion proteins containing the Gal4 DNA binding domain (DBD) alone or with VP16; nucleolin; catfish Oct $2 \beta$ N-terminus; and catfish Oct2 $\beta$ C-terminus have previously been described [32]. The Gal4DBD-Oct1 domain fusion expression constructs were produced by PCR and were directionally cloned into the Gal4DBD expression construct with XbaI and BamHI restriction enzyme sites. An internal stop codon was also included prior to the BamHI site. All clones were checked by sequencing before use to ensure the absence of PCRinduced mutations.

Primers:

Oct1 N-terminus

G - 2977 - 5' TTT TCT AGA GAG AAT GGA ATA CAT GGA GTC CAA 3'

G - 2978 - 5' TTT GGA TCC CTA TAG AGG AAC ATC CAC CCG CTT 3'

Oct1 POU domain

G - 2979 - 5' TTT TCT AGA GTG GAG GAG GCC AGT GAA CTG 3'

G - 2980 - 5' TTT GGA TCC CTA GTT GAT CCT CTT CTC CTT CTG 3'

Oct1 C-terminus 
G - 2981 - 5' TTT TCT AGA AAC CCC CCG AGC AGC AGC ACA 3'

G - 2982 - 5' TTT GGA TCC CTA TCA TTG CGC CTT GGA GGC CAC 3'

\section{Cell Lines and DNA transfection}

The catfish B lymphoblastoid cell line 1G8 and T cell line G14D, and the mouse plasmacytoma cell line J558L were maintained as previously described [50]. Transfections were performed with an Electro Cell Manipulator 600 (BTX, San Diego, Ca) and 2-mm gap cuvettes (BTX) were used. All cells were harvested during the logarithmic growth phase and washed once in serum free media (45\% AIMV, 45\% L15 and 10\% deionized water for catfish cells and RPMI-1640 for mouse cells) before resuspension in serum free media prior to transfection. Immediately before transfection $180 \mu \mathrm{L}$ of cells $\left(8 \times 10^{6}\right.$ cells of $1 \mathrm{G} 8$ and $4 \times 10^{6}$ cells of J558L) were mixed with $20 \mu \mathrm{L}$ of prepared DNA. Reporter construct (2.4 pM of pGL3/D56/ R\#2), (3.2 pM of pFVH-CAT), (3.3 pM of pO3- $\Delta 56-C A T)$ and empty, Oct1, Oct2 or BOB.1 expression vectors (1.6 pM) were transfected into the cells. For competition studies $1 \mathrm{pM}$ of Oct 2 construct was transfected, and increasing amounts of the Oct 1 construct were added; $0.5 \mathrm{pM}, 1 \mathrm{pM}$, and $2 \mathrm{pM}$. For the Gal4 studies $3.95 \mathrm{pM}$ of the pG5/CAT reporter construct was used. For the expression constructs, $1.108 \mathrm{pM}$ of Gal4-DBD alone, Gal4DBD bound to nucleolin, VP16, Oct2 $\beta$ N-Term, Oct2 $\beta$ C-term, Oct1 POU domain, Oct1 N-term, Oct1 C-term was transfected into the catfish $1 \mathrm{G} 8$ cell line. In all experiments $1 \mu \mathrm{g}$ of a Renilla luciferase construct with a CMV promoter (pRL/ $\mathrm{CMV}$; Promega) was used as the transfection control. Optimal transfection conditions were used as previously described [23]. Briefly, 1G8 cells were harvested at a density of 3.6-4.0 $\times 10^{6}$ cells $/ \mathrm{ml}$ and were electroporated at $210 \mathrm{~V}, 1100 \mu \mathrm{F}$, and $48 \Omega$. J558L cells were harvested at a density of $0.8-1.0 \times 10^{6}$ cells $/ \mathrm{ml}$ and electroporated at $130 \mathrm{~V}, 1100 \mu \mathrm{F}$, and $48 \Omega$. All transfected cells were harvested 36-40 hours after electroporation and assessed for expression of the reporter genes.

\section{Luciferase Reporter Assay}

Luciferase activity was measured using the Dual-luciferase reporter assay system (Promega) and a TD-20/20 luminometer (Turner Designs, Sunnyvale, CA). Transfection activity was normalized to the activity of the co-transfected Renilla luciferase, and the values were calculated as mean \pm standard deviation. Statistical analysis was performed using the Student's T-test assuming unequal variances.

\section{CAT Assay}

Cells were lysed in $1 \times$ Reporter Lysis Buffer (Promega) and split into two $100 \mu \mathrm{l}$ aliquots. One of the aliquots was used in the luciferase reporter assay as described above. The second aliquot was heated at $60^{\circ} \mathrm{C}$ for $10 \mathrm{~min}$. After heating and centrifugation $(16,100 \times \mathrm{g}$ for $2 \mathrm{~min})$ the supernatant was transferred into the CAT reaction mixture containing ${ }^{14} \mathrm{C}$ chloramphenicol, n-Butyryl CoA (Promega) and water to a final volume of $125 \mu \mathrm{L}$. The reactions were incubated at $37^{\circ} \mathrm{C}$ for 16 hours and then terminated by the addition of mixed xylenes (Sigma, St. Louis, MO) to extract the modified chloramphenicol. The extracted layer was then added to liquid scintillation fluid and the radioactive product was measured in a liquid scintillation counter. Assay results were normalized using the luciferase assay results and the values were calculated as mean \pm standard deviation. Statistical analysis was performed using the Student's T-test assuming unequal variances.

\section{Recombinant protein and antiserum production}

The sequence encoding the C-terminal region of catfish Oct1 was digested from the pBluescript vector (Stratagene) as an EcoRV fragment (taking advantage of restriction sites at position $1149-1154$ in the Oct1 coding sequence and in the multiple cloning site of the vector) and ligated into the SmaI restriction site of the pQE30 bacterial expression vector (Qiagen) that contains an N-terminal (His) ${ }_{6}$ tag. The plasmid was transformed into the Escherichia coli M15 strain (Qiagen) and grown at $37^{\circ} \mathrm{C}$ in LB medium containing a final concentration of $100 \mu \mathrm{g} / \mathrm{ml}$ ampicillin, $25 \mu \mathrm{g} / \mathrm{ml}$ kanamycin, and induced with $2 \mathrm{mM}$ IPTG (Sigma) 5 hours after reaching an $\mathrm{OD}_{600}$ of 0.7. The bacteria were harvested and resuspended in $5 \mathrm{ml}$ sonication buffer $(1 \mathrm{mM}$ phenyl methyl sulfonyl fluoride (PMSF), $6 \mathrm{M}$ urea, $400 \mathrm{mM} \mathrm{NaCl}, 50 \mathrm{mM} \mathrm{NaH}_{2} \mathrm{PO}_{4} \mathrm{pH}$ 8.0 ) and lysed by freeze thawing. A 50\% TALLON metal affinity resin slurry (BD Biosciences Clontech) equilibrated with sonication buffer was used to purify the Histagged Oct1 C-terminal peptide. The eluted protein was dialyzed against $50 \mathrm{mM}$ ammonium bicarbonate and subsequently lyophilized. The purified peptide was used to immunize rabbits (Cocalico Biologicals, Reamstown, PA) using primary immunization with complete Freund's adjuvant and boosting using incomplete Freund's adjuvant.

\section{Electrophoretic Mobility Shift Assays}

A probe was created to the consensus octamer motif for use in EMSA by annealing the oligonucleotides below (the octamer motif is underlined):

Forward Primer (G-656) - 5' CAATATGAATATGCAAATTACCT 3'

Reverse Primer (G-567) - 5' CATAGGTAATTTGCATATTCATA 3' 
A probe with a scrambled octamer sequence was produced by annealing the oligonucleotides below (the scrambled octamer motif is underlined):

Forward Primer (G-1249) - 5' CAATATGAATACAAAATATACCT 3'

\section{Reverse Primer (G-1250) - 5' CATAGGTATATTTTGTAT- TCATA 3'}

A probe was created to the first octamer motif located within the core enhancer of E $\mu 3$ ' using the oligonucleotides below (the octamer motif is underlined):

Forward Primer (G-2110) - 5' GCAAAACACTGCATGTAAATAGTCTAAT 3'

Reverse Primer (G-2111) - 5' CATTATTAGACTㅅTTACATGCAGTGTT 3 '

The scrambled probe to the first octamer motif located within the core enhancer of E $\mu 3$ ' was created using the oligonucleotides below (the scrambled octamer motif is underlined):

Forward Primer (G-2132) - 5' GCAAAACACTGCTATATGAAAGTCTAAT 3'

Reverse Primer (G-2133) - 5' CATTATTAGACTTTCATATAGCAGTGTT 3'

After annealing, the purity of the double-stranded DNA was verified by gel electrophoresis on a $6 \%$ non-denaturing polyacrylamide gel (BioRad). The annealed probes were labeled by a radioactive fill-in reaction using the large fragment of DNA polymerase I (Klenow Enzyme, Fisher, Suwanee, GA) and $\alpha$-32P-dATP (New England Nuclear, Boston, MA) and purified through two Microspin G-25 columns (Amersham Pharmacia Biotech). Nuclear extracts were obtained and EMSA was carried out as described by Ross et al [31]. The TNT quick-coupled transcription/translation system (Promega) was used to generate in vitro synthesized catfish Oct1 and Oct2 proteins. ${ }^{35}$ S-Methionine (New England Nuclear) labeled in vitro transcribed and translated proteins were analyzed by SDS-PAGE gel electrophoresis and autoradiography. Binding reactions included $4 \mu \mathrm{l}$ of $5 \times$ binding buffer (Promega), $6 \mu \mathrm{L}$ of TNT products, $2 \mu \mathrm{L}$ of normal rabbit serum (NRS, anti-Oct1 pre-bleed), cold or scrambled competitor (100 times the concentration of the labeled probe), and anti-Oct1 or anti-Oct2. These reactions were incubated at room temperature for 30 minutes prior to the addition of $1 \mu \mathrm{L}$ of the radiolabeled probe $\left(10^{6} \mathrm{cpm} /\right.$ $\mu \mathrm{l})$. After a 30 minute incubation the DNA-protein complexes were analyzed on a $5 \%$ non-denaturing polyacryla- mide gel, $150 \mathrm{~V}$ at $4^{\circ} \mathrm{C}$ with a recirculating cooling system. Gels were washed in 15\% methanol, 5\% acetic acid for 30 minutes and allowed to dry, before exposure to a Phosphoimager screen and analysis by a Typhoon Variable Mode Imager (Amersham Biosciences) and the ImageQuant software program.

\section{Authors' contributions}

ML assisted in the design of the study, carried out the sequence alignment, phylogenetic analysis, cloning of expression vectors and DNA constructs, upkeep of cell lines, RT-PCR, transfection studies, in vitro protein expression and EMSA, Gal4 activation studies and drafted the manuscript. JH assisted in the design of the study, the participated in the sequence alignment, assisted in the cloning of expression vectors, assisted with upkeep of cell lines, and helped draft the manuscript. DR cloned the Oct1 cDNA, assisted with transfection experiments, carried out in vivo EMSA and participated in revising the manuscript. CK assisted with the transfection experiments, produced the Oct1 antibody and participated in revising the manuscript. MW isolated RNA from catfish tissues and upkeep of cell lines and participated in revising the manuscript. NM assisted with the isolation of RNA, upkeep of cell lines and participated in the revising of the manuscript. GW conceived the study, participated in the design and coordination and helped draft the manuscript. All authors have read and approved the final manuscript.

\section{Acknowledgements}

This work was supported by awards from the National Science Foundation (MCB980753I) and the National Institutes of Health (R0I-GM623I7 and ROI-Al-19530). The costs of publication of this article were defrayed in part by the payment of page charges. This article must therefore be marked "advertisement" in accordance with I8 U.S.C. Section 1734 solely to indicate this fact. Publication \#14 from the Marine Biomedicine and Environmental Sciences Center.

\section{References}

I. Parslow TG, Blair DL, Murphy WJ, Granner DK: Structure of the 5' ends of immunoglobulin genes: a novel conserved sequence. Proc Natl Acad Sci USA 1984, 81:2650-2654.

2. Staudt LM, Lenardo MJ: Immunoglobulin gene transcription. Annu Rev Immunol 199I, 9:373-398.

3. LaBella F, Sive HL, Roeder RG, Heintz N: Cell-cycle regulation of a human histone $\mathrm{H} 2 \mathrm{~b}$ gene is mediated by the $\mathrm{H} 2 \mathrm{~b}$ subtypespecific consensus element. Genes Dev 1988, 2:32-39.

4. Carbon P, Murgo S, Ebel JP, Krol A, Tebb G, Mattaj LW: A common octamer motif binding protein is involved in the transcription of U6 snRNA by RNA polymerase III and U2 snRNA by RNA polymerase II. Cell I987, 5 I:7I-79.

5. Klemm JD, Rould MA, Aurora R, Herr W, Pabo CO: Crystal structure of the Oct-I POU domain bound to an octamer site: DNA recognition with tethered DNA-binding modules. Cell 1994, 77:21-32.

6. Phillips K, Luisi B: The virtuoso of versatility: POU proteins that flex to fit. J Mol Biol 2000, 302: 1023-1039.

7. Wegner M, Drolet DW, Rosenfeld MG: POU-domain proteins: structure and function of developmental regulators. Curr Opin Cell Biol 1993, 5:488-498. 
8. Spaniol P, Bornmann C, Hauptmann G, Gerster T: Class III POU genes of zebrafish are predominantly expressed in the central nervous system. Nucleic Acids Res 1996, 24:4874-488I.

9. Billin AN, Cockerill KA, Poole SJ: Isolation of a family of Drosophila POU domain genes expressed in early development. Mech Dev 199I, 34:75-84.

10. Char BR, Tan H, Maxson R: A POU gene required for early cleavage and protein accumulation in the sea urchin embryo. Development 1994, I 20:1929-1935.

II. Cupit PM, Lennard ML, Hikima JI, Warr GW, Cunningham C: Characterization of two POU transcription factor family members from the urochordate Oikopleura dioica. Gene 2006.

12. Wang VE, Schmidt T, Chen J, Sharp PA, Tantin D: Embryonic lethality, decreased erythropoiesis, and defective octamerdependent promoter activation in Oct-I-deficient mice. Mol Cell Biol 2004, 24:1022-1032.

13. Corcoran LM, Karvelas M, Nossal G], Ye ZS, Jacks T, Baltimore D Oct-2, although not required for early B-cell development, is critical for later B-cell maturation and for postnatal survival. Genes Dev 1993, 7:570-582.

14. Tanaka M, Herr W: Differential transcriptional activation by Oct-I and Oct-2: interdependent activation domains induce Oct-2 phosphorylation. Cell 1990, 60:375-386.

15. Muller-Immergluck MM, Schaffner W, Matthias P: Transcription factor Oct-2A contains functionally redundant activating domains and works selectively from a promoter but not from a remote enhancer position in non-lymphoid (HeLa) cells. Embo J 1990, 9:1625-1634.

16. LeBowitz JH, Kobayashi T, Staudt L, Baltimore D, Sharp PA: Octamer-binding proteins from B or HeLa cells stimulate transcription of the immunoglobulin heavy-chain promoter in vitro. Genes Dev 1988, 2:1227-1237.

17. Luo Y, Fujii H, Gerster T, Roeder RG: A novel B cell-derived coactivator potentiates the activation of immunoglobulin promoters by octamer-binding transcription factors. Cell 1992, 71:23|-24I.

18. Gstaiger M, Knoepfel L, Georgiev O, Schaffner W, Hovens CM: A Bcell coactivator of octamer-binding transcription factors. Nature 1995, 373:360-362.

19. Strubin M, Newell JW, Matthias P: OBF-I, a novel B cell-specific coactivator that stimulates immunoglobulin promoter activity through association with octamer-binding proteins. Cell 1995, 80:497-506.

20. Wang VE, Tantin D, Chen J, Sharp PA: B cell development and immunoglobulin transcription in Oct-I-deficient mice. Proc Natl Acad Sci USA 2004, I 0 I:2005-20I0.

21. Kim U, Qin XF, Gong S, Stevens S, Luo Y, Nussenzweig M, Roeder RG: The B-cell-specific transcription coactivator OCA-B/ OBF-I/Bob-I is essential for normal production of immunoglobulin isotypes. Nature 1996, 383:542-547.

22. Schubart K, Massa S, Schubart D, Corcoran LM, Rolink AG, Matthias $P$ : $B$ cell development and immunoglobulin gene transcription in the absence of Oct-2 and OBF-I. Nat Immunol 200I, 2:69-74

23. Cioffi CC, Middleton DL, Wilson MR, Miller NW, Clem LW, Warr GW: An IgH enhancer that drives transcription through basic helix-loop-helix and Oct transcription factor binding motifs. Functional analysis of the $E \mu 3$ ' enhancer of the catfish. I Biol Chem 200I, 276:27825-27830.

24. Wilson MR, Marcuz A, van Ginkel F, Miller NW, Clem LW, Middleton $D$, Warr GW: The immunoglobulin $M$ heavy chain constant region gene of the channel catfish, Ictalurus punctatus: an unusual mRNA splice pattern produces the membrane form of the molecule. Nucleic Acids Res 1990, 18:5227-5233.

25. Wilson M, Bengten E, Miller NW, Clem LW, Du Pasquier L, Warr GW: A novel chimeric Ig heavy chain from a teleost fish shares similarities to IgD. Proc Natl Acad Sci USA 1997, 94:4593-4597.

26. Bengten E, Quiniou S, Hikima J, Waldbieser G, Warr GW, Miller NW, Wilson M: Structure of the catfish IGH locus: analysis of the region including the single functional IGHM gene. Immunogenetics 2006, 58(10):83I-44.

27. Magor BG, Wilson MR, Miller NW, Clem LW, Middleton DL, War GW: An Ig heavy chain enhancer of the channel catfish Ictalurus punctatus: evolutionary conservation of function but not structure. J Immunol 1994, I 53:5556-5563.
28. Bengten E, Quiniou SM, Stuge TB, Katagiri T, Miller NW, Clem LW, Warr GW, Wilson M: The IgH locus of the channel catfish, Ictalurus punctatus, contains multiple constant region gene sequences: different genes encode heavy chains of membrane and secreted IgD. J Immunol 2002, 169:2488-2497.

29. Tian G, Erman B, Ishii H, Gangopadhyay SS, Sen R: Transcriptional activation by ETS and leucine zipper-containing basic helixloop-helix proteins. Mol Cell Biol 1999, 19:2946-2957.

30. Nikolajczyk BS, Cortes M, Feinman R, Sen R: Combinatorial determinants of tissue-specific transcription in B cells and macrophages. Mol Cell Biol 1997, 17:3527-3535

31. Ross DA, Magor BG, Middleton DL, Wilson MR, Miller NW, Clem LW, Warr GW: Characterization of Oct2 from the channel catfish: functional preference for a variant octamer motif. Immunol 1998, 160:3874-3882.

32. Cioffi CC, Pollenz RS, Middleton DL, Wilson MR, Miller NW, William Clem L, Warr GW, Ross DA: Oct2 transcription factor of a teleost fish: activation domains and function from an enhancer. Arch Biochem Biophys 2002, 404:55-61.

33. Prakash K, Fang XD, Engelberg D, Behal A, Parker CS: dOct2, a Drosophila Oct transcription factor that functions in yeast. Proc Natl Acad Sci USA 1992, 89:7080-7084.

34. Ross DA, Lyles M, Ledford BE, Magor BG, Wilson MR, Miller NW, Clem LW, Middleton DA, Warr GW: Catfish Oct2 binding affinity and functional preference for octamer motifs, and interaction with OBF-I. Dev Comp Immunol I999, 23:199-2II.

35. Riss J, Laskov R: Expression of novel alternatively spliced isoforms of the oct-I transcription factor. Biochim Biophys Acta 1999, 1444:295-298.

36. Wilson MR, Middleton D, Warr GW: Immunoglobulin VH genes of the goldfish, Carassius auratus: a re-examination. Mol Immunol 199|, 28:449-457.

37. Sturm RA, Das G, Herr W: The ubiquitous octamer-binding protein Oct-I contains a POU domain with a homeo box subdomain. Genes Dev 1988, 2:1582-1599.

38. Seipel K, Georgiev O, Schaffner W: Different activation domains stimulate transcription from remote ('enhancer') and proximal ('promoter') positions. Embo J 1992, I I:4961-4968.

39. Chasman D, Cepek K, Sharp PA, Pabo CO: Crystal structure of an OCA-B peptide bound to an Oct-I POU domain/octamer DNA complex: specific recognition of a protein-DNA interface. Genes Dev 1999, 13:2650-2657.

40. Yang F, Ventura-Holman T, Waldbieser GC, Lobb CJ: Structure, genomic organization, and phylogenetic implications of six new VH families in the channel catfish. Mol Immunol 2003 , 40:247-260.

4I. Mittal V, Ma B, Hernandez N: SNAP(c): a core promoter factor with a built-in DNA-binding damper that is deactivated by the Oct-I POU domain. Genes Dev 1999, I3:1807-I821.

42. Tanaka M, Lai JS, Herr W: Promoter-selective activation domains in Oct-I and Oct-2 direct differential activation of an snRNA and mRNA promoter. Cell 1992, 68:755-767.

43. Ryan AK, Rosenfeld MG: POU domain family values: flexibility, partnerships, and developmental codes. Genes Dev 1997 , I I: | 207-I 225 .

44. Cheng CK, Yeung CM, Hoo RL, Chow BK, Leung PC: Oct-I is involved in the transcriptional repression of the gonadotropin-releasing hormone receptor gene. Endocrinology 2002, | 43:4693-470I.

45. Kakizawa T, Miyamoto T, Ichikawa K, Takeda T, Suzuki S, Mori J, Kumagai M, Yamashita K, Hashizume K: Silencing mediator for retinoid and thyroid hormone receptors interacts with octamer transcription factor-I and acts as a transcriptional repressor. J Biol Chem 200I, 276:9720-9725.

46. Nogueira ML, Wang VE, Tantin D, Sharp PA, Kristie TM: Herpes simplex virus infections are arrested in Oct-I-deficient cells. Proc Natl Acad Sci USA 2004, 10 I: 1473-1478.

47. Tantin D, Schild-Poulter C, Wang V, Hache RJ, Sharp PA: The octamer binding transcription factor Oct- $I$ is a stress sensor. Cancer Res 2005, 65:10750-10758.

48. Vallejo AN, Ellsaesser CF, Miller NW, Clem LW: Spontaneous development of functionally active long-term monocytelike cell lines from channel catfish. In Vitro Cell Dev Biol 1991, 27A:279-286 
49. Kumar S, Tamura K, Jakobsen IB, Nei M: MEGA2: molecular evolutionary genetics analysis software. Bioinformatics 200I, I 7:1244-1245.

50. Hikima J, Cioffi CC, Middleton DL, Wilson MR, Miller NW, Clem LW, Warr GW: Evolution of transcriptional control of the IgH Locus: characterization, expression, and function of TF 12 I HEB homologs of the catfish. J Immunol 2004, 173:5476-5484. 